\title{
Improvement in diabetic neuropathy 4 years after successful pancreatic and renal transplantation
}

\author{
G. Solders ${ }^{1}$, G. Tydén ${ }^{2}$, A. Persson ${ }^{1}$ and C.-G. Groth ${ }^{2}$ \\ Departments of ${ }^{1}$ Clinical Neurophysiology and ${ }^{2}$ Transplantation Surgery, Karolinska Institute, Huddinge Hospital, Stockholm, \\ Sweden
}

Summary. We have studied the fate of diabetic neuropathy and autonomic function in 13 patients with long standing Type 1 (insulin-dependent) diabetes mellitus following combined pancreas and kidney transplantation. Fifteen diabetic patients with a kidney graft only served as controls. After initial improvement of the neuropathy in both groups, probably caused by the elimination of uraemia, a continuous improvement during the 48 months study was seen in the euglycaemic pancreas graft recipients only. Autonomic (parasympathetic) function improved only slightly and to a similar extent in both groups.

Key words: Diabetic neuropathies-Pancreas transplantation-Kidney transplantation-Autonomic nervous system.

\section{Introduction}

Polyneuropathy affecting motor, sensory and autonomic functions is common in patients with diabetes mellitus (cf Dyck et al, 1987). The exact prevalence is not known, but is estimated to about $50 \%$ after 25 years of Type 1 (insulin-dependent) diabetes mellitus (Pirart 1978). Polyneuropathy and autonomic dysfunction are also common in end-stage uraemia (Arieff 1986; Thomas 1976) and thus, diabetic nephropathy may add to the already existing diabetic peripheral nerve dysfunction.

We have earlier shown that two years of normoglycaemia after combined pancreatic and kidney transplantation $(\mathrm{P}+\mathrm{K}-\mathrm{tx})$ resulted in only a minor improvement of the neuropathy and that the results did not differ significantly from a control group with a kidney transplant $(\mathrm{K}$ tx) only. Furthermore, we found no improvement in autonomic function (R-R test) (Solders et $\mathrm{al}_{8}$ 1987). Similar results with halt of the expected progression, but little or slight improvement of the neuropathy in one to two year follow-up studies after pancreas trans- plantation have been reported by others (Sutherland et al. 1986; Van der Vliet et al. 1988; Bartos et al. 1986; Traeger et al.1986; Landgraf et al.1986; Beggs et al. 1990). Recently, Kennedy et al. (1990) reported a tendency towards improvement of the neuropathy in 11 patients studied 42 months after pancreas transplantation, whereas in the insulin-treated control group the neuropathy tended to worsen.

The aim of this study was to examine whether four years of normoglycaemia after combined $\mathrm{P}+\mathrm{K}$-tx could halt the progression of the neuropthy, or even restore peripheral nerve function and autonomic functions. A control group of diabetic patients with a renal graft only was included to see if the changes found could be due to the curing of uraemia or whether an additional improvement could be observed which could be due to the normoglycaemia induced by the pancreatic transplantation.

\section{Subjects and methods}

Eighteen patients undergoing combined $P+K-t x$ were initially admitted to the study. Five patients were excluded during the study, 2 because they died (intracerebral haemorraghia, cardiac infarction) and 3 because of late pancreas graft rejection. Thus, 13 patients $(9$ male, $4 \mathrm{fe}$ male) aged 30-44 remained in the study for at least 4 years. $4 / 13$ patients were on dialysis prior to $\mathrm{P}+\mathrm{K} \mathrm{tx}$.

The control group consisted of 18 patients who lost their pancreatic graft early or who received a K-tx only (4 patients). Three control patients were excluded during the study, 2 because they died (cardiac failure, cardiac infarction) and 1 because of late renal graft rejection. The remaining 15 control patients ( 8 male, 7 female) aged 30 53 remained in the study for at least 4 years. 13/15 of the control subjets were on dialysis prior to $\mathrm{K}-\mathrm{tx}$.

All patients had long standing Type 1 diabetes mellitus ( $25 \pm 4$ years in the $K+P$-tx group, $26 \pm 7$ years in the control K-tx group).

Transplantation. The surgical technique has been described earlier (Groth et al.1982; Tydén et al,1986). Enteric 
diversion of the exocrine secretion was used. All pancreatic grafts were obtained from cadaveric donors and for the combined $t x$ the kidney came from the same donor. For renal transplantation alone, 16 kidneys came from cadaveric donors and 2 from living related donors. Immunosupression consisted of cyclosporine, azathioprine, prednisolone and rabbit anti-thymocyte globuline. Rejection was treated with methylprednisolone iv for 4 days.

Recording procedure. Nerve conduction studies were with conventional neurophysiological techniques. Ten variables were recorded: motor conduction velocity (MCV) and distal latency (DL) in the median and peroneal nerves and sensory conduction velocity (SCV) and the amplitude of the sensory nerve action potential (SNAP) in the distal and proximal median nerve and in the sural nerve. Care was taken to make all recordnings at normal skin temperature. The $R-R$ variations in the electrocardiogram were recorded and the variations relative to mean $R-R$ interval during $1 \mathrm{~min}$ of deep breathing ( 6 breaths $/ \mathrm{min}$ ) were calculated. Our normal value for this age group is 30 $\pm 9 \%$. Recording procedure and calculations have been described earlier (Persson and Solders 1983).

Statistical methods. Values are given as mean \pm SD. The degree of polyneuropathy was expressed as an index, ENeG-Ix, which is the mean deviation of the recorded variables (in SD) from normal age-matched laboratory controls. The normal limit of ENeG-Ix for individuals $(p<0.05)$ is $\pm 2 / \sqrt{\text { number }}$ of recorded variables, in this study ie. \pm 0.63 . Differences between the groups were tested by the two-tailed $t$-test and intraindividual differences over time were tested by the two-tailed t-test of differences. The level of significance was set to $\mathrm{p}<0.05$ (Snedecor and Cochran 1980).

\section{Results}

Exogenous insulin could be discontinued in all patients in the $\mathrm{P}+\mathrm{K}-\mathrm{tx}$ group. Glycosylated haemoglobin, $\mathrm{HbA} 1 \mathrm{c}$, was normal $(<5 \%)$ in 8 patients and near normal $(<7 \%)$ in 5 patients. The mean value was $4.9 \pm 0.5$. In the K-tx group the $\mathrm{HbA}_{1 \mathrm{c}}$ level was near normal in one patient but elevated in the remaining 14 . The mean value was $9.5 \pm 2.0$. S-kreatinin levels were moderately elevated in both groups after four years $(233 \pm 192$ in the $\mathrm{P}+\mathrm{K}$-tx and $228 \pm 104 \mu \mathrm{mol} / 1$ in the K-tx group, normal $<115 \mu \mathrm{mol} / \mathrm{l})$.

Before tx, all patients had neurophysiological signs of moderate or severe polyneuropathy. The ENeG-Ix indicated a slightly, but not significantly, more marked neuropathy in the control (K-tx) group (-2.89 \pm 0.76$)$ compared to the $\mathrm{P}+\mathrm{K}-\mathrm{tx}$ group $(-2.52 \pm 0.75)$. After the transplantation both groups improved in ENeG-Ix.

Within the $P+K-t x$ group a significant $(p<0.01) \mathrm{im}$ provement in ENeG-Ix was seen after 24 months and continous additional improvement was seen up to 48 months $(p<0.001)$. In the $\mathrm{K}$-tx group an initial improvement $(\mathrm{p}<0.01)$ of ENeG-Ix was seen during the first 24 months, after which no further improvement was seen, but instead a slight deterioration. After four years the ENeG-Ix in the P+K-tx group was $-1.79 \pm 0.72$ vs $2.25 \pm 0.81$ in the control K-tx groun.
Even after 48 months all patients except one (in the $\mathrm{P}+\mathrm{K}$-tx group) still had ENeG-Ix indicative of neuropathy. The difference in ENeG-Ix between the groups never reached significance (mean difference $0.46 \mathrm{SD}$ after 48 months). Significant intraindividual improvement of the ENeG-Ix $(>+0.63 \mathrm{SD}$, ie. $p<0.05)$ was seen in 9/13 (mean $+0.73 \mathrm{SD}$ ) in the $\mathrm{P}+\mathrm{K}$-tx group and in $7 / 15$ (mean $+0.64 \mathrm{SD}$ ) in the K-tx group.

The $R-R$ variation during deep breathing was equally low in both groups ( $p<0.001$ vs laboratory age-matched controls) before the transplantation.

After the transplantation a slight improvement $(p<0.05)$ was seen in both groups between $0-48$ months.

\section{Discussion}

This prospective study shows that diabetic neuropathy had improved 48 months after combined pancreatic and renal transplantation. Intraindividual improvement over time was more marked in the study group as compared to the control group receiving a renal graft only. The initial improvement in the control group can probably be explained by the fact that it contained more patients on dialysis prior to $t x$ than did the $\mathrm{P}+\mathrm{K}$-tx group (13/15 vs $4 / 13$ ) and, thus, the control patients probably had a larger component of uraemic neuropathy that responded to the renal tx. Furthermore, the patients in the P+K-tx group continued to improve throughout the study, whereas the ENeG-Ix in the still diabetic K-tx group deteriorated during the last two years. Thus, although the initial improvement seen in both groups may well be a result of the elimination of uraemia, the course between 24 and 48 months demonstrates that the normoglycaemic pancreas $t x$ recipients were further able to improve their nerve function, whereas the still diabetic renal tx group could not.

Other studies on nerve function one to two years following pancreas $t x$ have shown similar results, with a halt of the progression of neuropathy (Solders et al 1987; Sutherland et al.1986; Van der Vliet et al.1988; Bartos et al. 1986; Traeger et al. 1986; Landgraf et al. 1986; Beggs et al. 1990). Recently, Kennedy et al. (1990), using similar techniques to ours, found improvement in nerve function 12 months (61 patients), 24 months (27 patients) and a slight but not significant improvement 42 months (11 patients) after pancreas tx (in most cases without a simultaneous kidney graft).

The autonomic function was assessed by the R-R variation test during deep breathing. This is a sensitive test of the parasympathetic vagal reflex arc both in diabetes (Ewing et al.1981) and in uraemia (Solders et al. 1986), providing that consideration is taken to age (Wieling et al.1982; Persson and Solders 1983; Stålberg and Nogués 1989). The autonomic dysfunction was severe in all patients before $\mathrm{t} x$ and only a minor improvement was seen after four years (but not earlier) which was similar in both groups. In contrast to somatic nerve function (ENeG), impaired R-R variations in non-diabe- 
tic uraemic patients do not improve within one year after renal transplantation (Solders et al.1986). The cause of the improvement in R-R variations in both our groups may be a long-term effect of the elimination of uraemia. An additional effect of four years euglycaemia in the pancreas tx group could explain the slight, but not significant, additional improvement in this group. Kennedy et $\mathrm{al}_{.}(1990)$ found a slight, but not significant, improvement in autonomic tests (R-R variation and Valsalva) 42 months after pancreas tx and the same group also reported no improvement in small nerve fibre functions (sweating and temperature) two years after pancreas tx (Kennedy et al.1989). Thus, in diabetic neuropathy thin myelinated and unmyelinated nerve fibres seem to recover less or at a slower rate than thick myelinated fibres after pancreas $t x$.

In conclusion: combined pancreatic and renal transplantation in patients with long standing Type 1 diabetes mellitus improved peripheral nerve function. An initial improvement was probably due to the elimination of uraemia. Subsequently further improvement was seen, probably due to nerve repair and regeneration under euglycaemia. Autonomic (parasympathetic) function improved only slightly and not more after combined transplantation than after kidney transplantation alone.

\section{References}

Arieff AI (1986) Neurological manifestations of uremia. In:Brenner BM, Rector FC (eds) The Kidney. WB Saunders,Philadelphia, pp 1731-1756

Bartos V, Venek I, Saudek F, Kocandrle V, Pavel P, Vondra K (1986) Comparison of the effects of pancreas and kidney transplantation with conventional treatment in diabetes. Transplant Proc 18:1768-1769

Beggs JL, Johnson PC, Olafsen AG, Cleary CP, Watkins CJ, Targovnik JH, Koep LJ (1990) Signs of nerve regeneration and repair following pancreas transplantation in an insulin-dependent diabetic with neuropathy. Clin Transplantation 4:133-141

Dyck PJ, Thomas PK, Asbury AK, Winegrad AI, Porte Jr D (1987) Diabetic Neuropathy. WB Saunders, Philadelphia London Toronto Mexico City Rio de Janeiro Tokyo Hong Kong.

Ewing DJ, Borsey DQ, Bellavere F, Clarke BF (1981) Cardiac autonomic neuropathy in diabetes: Comparison of measures of $R-R$ interval variations. Diabetologia 21:18-24

Groth C-G, Collste H, Lundgren G, Wilczek $H$, Klintmalm G, Ringden $O$, Gunnarsson $R$, Ostman $J$ (1982) Successful outcome of segmental human pancreatic transplantation with enteric exocrine diversion after modification in technique. Lancet 2:522-524

Kennedy WR, Navarro X, Sutherland DER (1989) Small nerve fiber neuropathy in diabetes mellitus after pancreas transplantation. Muscle \& Nerve 9:767

Kennedy WR, Navarro X, Goetz FC, Sutherland DER, Najarian JS (1990) Effects of pancreatic transplantation on diabetic neuropathy. $N$ Eng J Med 322:10311037

Landgraf R, Landgraf-Leurs MMC, Burg D, Kamplik A, Castro LA, Abendroth A, Illner WD, Land W (1986) Long-term follow-up of segmental pancreas transplan- tation in type I diabetics. Transplant Proc 18:11181124

Persson A, Solders G (1983) R-R variations, a test of autonomic dysfunction. Acta Neurol Scand 67:285-293

Pirart J (1978) Diabetes mellitus and its degenerative complications: A prospective study of 4400 patients observed between 1947 and 1973. Diabetes Care 1:168-188

Snedecor GW, Cochran WG (1980) Statistical Methods. 7th edn. Iowa State University Press, Ames

Solders G, Persson A, Wilczek H (1986) Autonomic system dysfunction and polyneuropathy in nondiabetic uremia. A one year follow-up study after renal transplantation. Transplantation 41:616-619

Solders G, Wilczek H, Gunnarsson R, Tydén G, Persson A, Groth C-G (1987) Effects of combined pancreatic and renal transplantation on diabetic neuropathy: $A$ two-year follow-up study. Lancet 2:1232-1235

Stålberg EV, Nogués MA (1989) Automatic analysis of heart rate variation: 1 . Method and reference values in healthy controls. Muscle \& Nerve 12:993-1000

Sutherland DER, Goettz FC, Hesse UJ et al.(1986) Effect of multiple variables on outcome in pancreas transplant recipients of the University of Minnesota and preliminaryobservations on the course of pre-existing secondary complications of diabetes. In: Friedman EA, L'Esperance FA Jr (eds) Diabetic renal-retinal syndrome: prevention and management, Vol. 3. Grune \& Stratton, New York, pp 481-499

Thomas PK (1976) Uraemic neuropathy. Proc Eur Dial Transpl Assoc 13:109-118

Traeger J, Monti LD, Dubernard JM, Toraine JL, Piatti PM, Bosi E, Cantarovich D, Lefrancois N, Secchi A, Pozza G (1986) Metabolic studies and follow-up of degenerative complications in patients with a long-term functioning pancreatic graft (more than 1 year). Transplant Proc 18:1139-1140

Tydén G, Lundgren G, Ost L, Kojima X, Gunnarsson R, Ostman J, Groth CG (1986) Progress in segmental pancreatic transplantation. World J Surg 10:404-409

Van der Vliet JA, Navarro X, Kennedy WR, Goetz FC, Najarian JS, Sutherland DE (1988) The effect of pancreas transplantation on diabetic polyneuropathy. Transplantation 45:368-370

Wieling W, van Brederode JFM, de Rijk LG, Borst C, Dunning AJ (1982) Reflex control of the heart rate in normal subjects in relation to age: $A$ data base for cardial vagal neuropathy. Diabetologia 22:163-166

\author{
Dr. G. Solders \\ Department of Clinical Neurophysiology \\ Huddinge University Hospital \\ S-141 86 Huddinge \\ Sweden
}

